\title{
DIETA RICA EM GORDURA E SUA RELAÇÃO COM O PROCESSO CARCINOGÊNICO
}

DIET RICH IN FAT AND ITS RELATION TO CARCINOGENIC PROCESS

\author{
BOLLER, Guilherme Comin ${ }^{1,2}$; FALDONI, Flávia Lima Costa ${ }^{1,2,3}$ \\ ${ }^{1}$ Centro Universitário Hermínio Ometto - FHO|Uniararas; ${ }^{2}$ Biomédico; ${ }^{3}$ Docente do curso de \\ Biomedicina e Farmácia. \\ flaviafaldoni@uniararas.br
}

RESUMO. A etiologia do câncer envolve múltiplos fatores, estudos já têm comprovado o hábito alimentar como um dos fatores relevantes na proliferação de células tumorais. Analisando este fator de risco na sociedade atual, principalmente a ocidental, em que a alimentação tem sido descuidada devido ao cotidiano conturbado e movimentado da maioria das pessoas e a rapidez e praticidade oferecida pelas empresas alimentícias, fica em evidência o aumento da ingestão de alimentos de baixo valor nutritivo e com maiores quantidades de gorduras. A dieta rica em gordura pode contribuir com o processo carcinogênico, considerando que o excesso de ácidos graxos, entre outros produtos do metabolismo lipídico, é responsável pelo estímulo do crescimento celular, já que estes são utilizados como sinalizadores celulares; constituintes da formação de membrana celular e de componentes citoplasmáticos, além de contribuir para a manutenção da célula através das reservas de energia. Estudos recentes demonstram as alterações que o câncer promove no metabolismo de lipídios a fim de atender as suas necessidades e promover a rápida proliferação no sistema. Em conjunto às novas descobertas sobre o mecanismo de influência da gordura exógena no câncer, surgem novas possibilidades da sua utilização para tratamento e diagnóstico. Diante do exposto, este trabalho tem por objetivo fazer uma revisão bibliográfica, nas principais bases de dados, buscando esclarecer os mecanismos moleculares que envolvem o excesso de lipídios com o aumento da incidência de câncer, assim como o controle da dieta como meio preventivo e terapêutico.

Palavras-chave: lipídios, metabolismo intracelular, células cancerígenas.

\begin{abstract}
The cancer etiology is multifactorial; however, studies have proven the feeding habits as one of the relevant factors in the proliferation of cancer cells. Analyzing this risk factor in today's society, especially the West, where the food has been neglected due to the troubled and busy daily lives of most people and the speed and convenience offered by food companies, is highlighted increased intake of food low nutritional value and with higher amounts of fat. It is known that highfat diet can contribute to carcinogenesis process, whereas the excess fatty acids and other products of lipid metabolism, is responsible for stimulating cell growth, since they are used as cellular signal; are also constituents of the cell membrane and cytoplasmic components, besides contributing to the maintenance of the cell through the energy reserves. Recent studies have also shown the changes that cancer promotes the lipid metabolism, such as increasing: absorption, inflammation and expression of proteins related to this process in order to meet their needs and promote the rapid proliferation in the system. Together with the new findings on the mechanism of influence of exogenous fat in cancer, there are new possibilities of their use for treatment and diagnosis. Given the above, this work aims to make a literature review, seeking to clarify the molecular mechanisms involving excess of lipids with increasing incidence of cancer, as well as control diet as a preventive and therapeutic.
\end{abstract}

Keywords: lipids, intracellular metabolism, cancer cells. 


\section{INTRODUÇÃO}

O câncer tem notavelmente se tornado um problema de saúde pública e também um dos principais focos de pesquisas e estudos na área da saúde. Tal tendência pode ser justificada pelos últimos dados publicados no World Cancer Report 2014, pela International Agency for Research on Cancer (Iarc), a qual relata que nas próximas décadas, o impacto do câncer na população corresponda a $80 \%$ dos mais de 20 milhões de novos casos, estimados para 2025 (BRASIL, 2016).

A definição de câncer, segundo o Instituto Nacional de Câncer (BRASIL, 2016) é descrita como um conjunto de mais de 100 doenças que têm em comum o crescimento desordenado (maligno) de células que invadem os tecidos e órgãos, podendo espalhar-se para outras regiões do corpo (metástase).

Apesar de o câncer ser diversificado em relação à sua etiologia, é reconhecido que fatores externos ou internos podem influenciar em seu desenvolvimento, causando as alterações necessárias no organismo para a promoção do mesmo. Especificamente nas causas externas, observa-se que tanto o meio ambiente como os hábitos e costumes típicos de um determinado contexto sociocultural são determinantes para a promoção deste quadro patológico (BRASIL, 2016).

A dieta do organismo é um dos vários fatores de estilo de vida que influenciam na incidência e progressão do câncer, sendo que a nutrição participa na etiologia em cerca de $40 \%$ dos casos de câncer em homens e $60 \%$ dos casos em mulheres. (ARNOT, 1998).

A esse respeito, também considera-se que:

O consumo de alimentos pode afetar diretamente a disponibilidade de nutrientes e indiretamente modular os níveis de fatores de crescimento e hormônios, que por sua vez, podem regular a homeostase do tecido e iniciar o tumor (RAFALSKI et al., 2012).

Particularmente, a dieta do ocidente é caracterizada pelo aumento da ingestão de gorduras e de alimentos de baixo valor nutritivo, acompanhada pela ascendência das redes de fast-food e do excessivo consumo de alimentos industrializados (WANDERLEY; FERREIRA, 2010). Tal modelo de dieta já tem se propagado por outras partes do mundo, e consequentemente, tem se observado o aumento de problemáticas na saúde pública como aterosclerose, hipertensão arterial, obesidade, diabetes e câncer (FELICIO, 2005).

Portanto, este trabalho tem por objetivo fazer uma revisão bibliográfica sobre o papel da dieta rica em gordura nos mecanismos que desenvolvem a progressão do câncer, elucidando os principais processos afetados e perspectivas da utilização deste fator etiológico como meio preventivo e terapêutico.

\section{METODOLOGIA}

A metodologia utilizada consistiu no acesso aos bancos de dados Scielo, PubMed, MEDLINE, Bireme e Biblioteca Virtual da FHO/Uniararas, buscando literaturas que foram publicadas entre os anos de 2000 e 2016.

\section{REFERENCIAL TEÓRICO}

Os lipídios e suas funções no organismo 
Os lipídios são compostos orgânicos, de origem biológica, essenciais como alimento para o corpo, geralmente insolúveis em água e solúveis em solventes orgânicos não polares (éter, clorofórmio, benzeno etc.). Possuem funções importantes no organismo, como: reserva de energia, componentes da estrutura de membranas celulares, ação hormonal, isolamento térmico, sinalização intracelular e extracelular, revestimento e proteção dos órgãos contra choques mecânicos (MARZZOCO; TORRES, 2015).

Esses compostos, quando hidrolisados produzem os ácidos graxos, os quais são ácidos orgânicos de cadeia linear, encontrados em gorduras naturais (SACKHEIM; LEHMAN, 2001). Podem ser classificados em saturados, quando contêm apenas ligações simples entre os átomos da cadeia carbônica; insaturados, quando contêm algumas ligações duplas entre os átomos de carbono; e poli-insaturados quando contêm muitas ligações duplas (MARZZOCO; TORRES, 2015). Nosso organismo é capaz de sintetizar ácidos graxos, porém, existem ácidos graxos essenciais que são obtidos somente pela dieta, sendo eles os ácidos graxos: linoleico e linolênico (insaturados) (SACKHEIM; LEHMAN, 2001).

A classificação dos lipídios pode ser feita em: (1) Lipídios simples - os quais são ésteres de ácidos graxos com algum tipo de álcool (glicerídeos - óleos e gorduras, cerídeos ceras); (2) Lipídios compostos - possuem a mesma composição dos lipídios simples, porém ligados a átomos de fósforo e nitrogênio (fosfolipídios e glicolipídios); (3) Lipídios precursores e derivados - os precursores são produzidos a partir da hidrólise de lipídios simples e compostos (ácidos graxos, glicerol, esfingosina e outros álcoois), já os derivados são produtos da metabolização de ácidos graxos (corpos cetônicos, esteróides, prostaglandinas, aldeídos graxos e vitaminas lipossolúveis) (ARANHA, 1998).

Segundo Ucko (1992), aproximadamente $42 \%$ das calorias ingeridas vêm dos lipídios, sendo que a composição destas gorduras na dieta ocidental, tendo como exemplo a norteamericana, é composta de $16 \%$ de gorduras saturadas e $26 \%$ de poli e monoinsaturadas. A quantidade de lipídios no sangue é reflexo da quantidade de ácidos graxos saturados e insaturados presentes na dieta, sendo que quanto mais saturadas as gorduras ingeridas, mais altas são as concentrações relativas de lipídios, possibilitando, uma maior propensão às doenças relacionadas a hiperlipemia (SANTOS et al., 2013).

Os lipídios da dieta têm sua digestão efetivamente iniciada no intestino delgado, onde são emulsificados na porção do duodeno pela ação de sais biliares, além também de sofrer a ação de enzimas hidrolíticas do suco pancreático (lipase-pancreática, colesterol esterase e fosfolipase $\mathrm{A}_{2}$ ), tendo como produto dessa ação os ácidos graxos e glicerol, colesterol, e fosfoglicerídeos, respectivamente (MOTTA, 2003). Esses produtos da lipólise são incorporados às miscelas mistas com sais biliares conjugados, as quais atuam como veículos dos ácidos graxos, levando-os da luz intestinal para a superfície das células da mucosa intestinal onde ocorrerá a absorção (NELSON; COX, 2002).

Após a absorção pelas células da mucosa intestinal, os ácidos graxos são destinados de acordo com o comprimento de suas cadeias, podendo ser liberados diretamente para a veia porta hepática ligados à albumina, quando apresentarem cadeia curta (2-10 átomos de carbono), ou, quando tiver cadeia longa, ser novamente convertidos a triglicerídeos e agrupados a apolipoproteínas, fosfolipídios e colesterol e, posteriormente, liberados para os vasos linfáticos intestinais, depois para a corrente sanguínea e finalmente, para as células do corpo, onde podem ser oxidados para gerar energia, utilizados na produção de membranas e organelas, e armazenados como reservas de energia (MOTTA, 2003; VOET; VOET; PRATT, 2014).

Os triglicerídeos são os lipídios mais comuns, sendo formados por três ácidos graxos, cada um em ligação éster com o mesmo glicerol. Essas gorduras vêm tanto de fontes animais 
(manteiga do leite de vaca, banha de porco, sebo da carne bovina e caprina) como vegetais (óleo de milho, de oliva, de amendoim e de açafrão), e são armazenados como reservas de energia, sendo que em períodos de jejum prolongado e em resposta ao estresse, os triglicerídeos armazenados nos adipócitos são hidrolisados em ácidos graxos e glicerol pela ação da lipase hormônio-sensível (NELSON; COX, 2002; MOTTA, 2003). Essa lipase é ativada pela ação dos hormônios epinefrina, norepinefrina, glucagon e hormônio adrenocorticotrófico (ACTH), sendo que nos adipócitos esses hormônios ligam-se a receptores que ativam a adenilato ciclase, a qual transforma ATP (Adenosina trifosfato) em AMPc (Adenosina monofosfato cíclico). O nível aumentado de AMPc estimula a Proteína quinase A, que fosforila e ativa a lipase, promovendo assim a lipólise (DE ROBERTIS; HIB, 2006).

Os fosfolipídios são formados por dois ácidos graxos (caudas hidrófobicas), um glicerol (cabeça hidrofílica), um segundo álcool e um radical fosfato, tornando-se assim moléculas anfipáticas (DE ROBERTIS; HIB, 2006). Na superfície de uma célula, os fosfolipídios fazem contato entre lipídios insolúveis em água com substâncias hidrossolúveis, como proteínas. Também estão envolvidos no transporte de ácidos graxos e outros processos, porém, sua principal função é a formação de membranas celulares (ARANHA, 1998).

Os esfingolipídios não possuem o glicerol, porém, contêm como base o aminoálcool esfingosina. Essas moléculas estão distribuídas em pequenas quantidades em plantas e animais, sendo importantes componentes da membrana celular. Eles podem ainda subdividirse em: esfingomielinas (um dos principais esfingolipídios), cerebrosídeos e gangliosídeos. (DE ROBERTIS; HIB, 2006).

Os esteróides são lipídios estruturais e estão presentes na maioria das membranas celulares. Sua estrutura característica é o núcleo esteróide, o qual consiste de quatro anéis fundidos, três com seis carbonos e um com cinco. Além da função como constituintes de membrana, os esteróides servem como precursores de vários produtos com atividades biológicas específicas, sendo esses o colesterol (o mais importante esterol no tecido animal e é fabricado pelo nosso corpo bem como obtido da dieta), vitamina $\mathrm{D}$, os sais biliares e muitos hormônios reguladores dos processos químicos (VOET; VOET; PRATT, 2014).

Os eicosanóides são um grupo de compostos com atividade biológica, derivados do ácido araquidônico. Eles são compostos extremamente potentes com uma variedade de ações, sendo eles: as prostaglandinas, os tromboxanos, prostaciclina e leucotrienos (BAYNES; DOMINICZAK, 2010). As prostaglandinas consistem de ácidos graxos insaturados, responsáveis pelas funções relacionadas à secreção de suco gástrico, contração e relaxamento muscular, inflamação, permeabilidade vascular, temperatura corporal e agregação plaquetária (BAYNES; DOMINICZAK, 2010). As prostaciclinas são potentes inibidores da agregação plaquetária e da vasodilatação. Já os tromboxanos são aglutinadores de plaquetas, apresentam contração dos vasos e em conjunto com a prostaciclina, ajudam na manutenção do sistema vascular (SACKHEIM; LEHMAN, 2001; BAYNES; DOMINICZAK, 2010). E os leucotrienos são um grupo de eicosanóides relacionados com as respostas alérgicas do corpo (SACKHEIM; LEHMAN, 2001; BAYNES; DOMINICZAK, 2010).

\section{Lipídios da dieta x metabolismo do câncer}

Considerando-se a importância dos lipídios em geral no nosso organismo e a sua presença na dieta de muitas pessoas, nos últimos anos, pesquisadores têm buscado elucidar os mecanismos pelos quais eles têm influenciado no processo carcinogênico e como eles são alterados. 
As reprogramações metabólicas têm sido bastante abordadas nos últimos estudos sobre câncer, considerando suas principais características definidas por Hanahan e Weinberg (2011) como: autossuficiência em sinais de crescimento, insensibilidade para sinais de inibição de crescimento, evasão da morte celular programada, potencial ilimitado de replicação, angiogênese sustentada e a capacidade de invadir tecidos e criar metástases. As células do câncer reprogramam vias metabólicas a fim de sustentar essas características (HANAHAN; WEINBERG, 2011; TEIXEIRA, 2007; MUÑOZ-PINEDO; MJIYAD; RICCI, 2012).

Especificamente, no metabolismo de lipídios, têm se observado que a síntese de lipídios está alterada no câncer, sendo que a via anabólica de lipídios é aumentada para suprir a proliferação celular exacerbada, tal característica é confirmada pelo aumento da expressão de enzimas relacionadas à sinalização celular e à lipogênese (DEBERARDINIS; CHANDEL, 2016). Porém, alguns autores, têm demonstrado através de seus estudos que apesar da maioria dos processos cancerígenos utilizarem a via glicolítica lática como meio de produção de energia (Efeito Warburg), alguns canceres como o de próstata, lipossarcoma, colorretal e mama, utilizam a $\beta$-oxidação de ácidos graxos como via energética preferencial (HANAHAN; WEINBERG, 2011; BALABAN et al, 2015).

Através de um estudo, Beloribi-Djefaflial et al. (2015) mostraram que células do câncer altamente proliferativas possuem uma forte avidez por lipídios e colesterol (tanto os absorvidos da dieta como os endógenos), e o excesso desses lipídios são armazenados nessas células na forma de gotas lipídicas ("lipid doplets"), sendo que altas concentrações dessas gotas lipídicas e de colesterol estão sendo considerados como características de agressividade do câncer, uma vez que foram encontradas maiores quantidades nas células malignas em comparação às células não malignas e células saudáveis. É possível que tal relação seja devido aos papéis essenciais que essas organelas desempenham na sinalização celular, regulação do metabolismo lipídico, tráfego da membrana e o controle da síntese e secreção de mediadores inflamatórios (BELORIBI-DJEFAFLIAL; VASSEUR; GUILLAUMOND, 2016; ABRAMCZYK, H. et al, 2015).

Também, sabe-se que as células cancerosas acabam desenvolvendo ambientes onde há baixa disponibilidade de oxigênio, nutrientes e vascularização irregular, já que sua intensa atividade celular e proliferação desenfreada não são reguladas de acordo com as condições ao seu redor. Porém, mediante a isso, foi demonstrado que as células do câncer acabam utilizando lipídios insaturados exógenos, já que na condição de hipóxia a célula não consegue sintetizar novos ácidos graxos, então, a fim de evitar o estresse oxidativo do retículo endoplasmático, o qual ocorre no aumento de lipídios saturados, e também, a apoptose decorrente, a célula aumenta a absorção de lipídios insaturados da dieta (ACKERMAN et al., 2014; AL-ZHOUGHBI et al., 2014).

O aumento da expressão de proteínas relacionadas ao metabolismo dos ácidos graxos tem também sido associado ao microambiente promovido pela alta ingestão de gorduras. Proteínas de transporte como CD36 (Translocase de ácidos graxos), FATP 1-6 (Proteínas de transporte de ácidos graxos), FABP (Proteínas de ligação de ácidos graxos) são altamente expressas promovendo maior absorção e mobilização destes lipídios para a esterificação e oxidação dos mesmos (BALABAN et al., 2015).

$\mathrm{Na}$ via de esterificação dos ácidos graxos, a qual produzirá os lipídios complexos que serão utilizados na construção de estruturas celulares e no armazenamento em forma de triglicerídeos, o aumento das enzimas 1-acilglicerol-3-fosfato-O-aciltransferase (AGPAT) e diacilglicerol aciltransferase (DGPAT) são mostrados através de análises experimentais em ratos obesos alimentados com dieta rica em gordura, o que auxilia na compreensão da relação desse fator alimentar com o câncer, já que os intermediários de lipídios da via de esterificação 
podem atuar como sinais lipídicos que modificam as estruturas de membrana e promovem a transcrição de genes para o crescimento celular, proliferação e diferenciação (CURI et. al., 2015).

$\mathrm{Na}$ via de oxidação, também são apontadas alterações nas enzimas correspondentes, iniciando-se na Acil-CoA Sintase (ACS), enzima que ativa os lipídios ligando Acil-Coa neles para serem utilizados na oxidação. Evidências científicas mostram que a ACS 3 e 5 estão associadas ao aumento da oxidação de ácidos graxos e a ACS 4 com a redução do nível de apoptose induzida por ácido araquidônico. $\mathrm{O}$ aumento da expressão gênica da Carnitina Palmitoiltransferase 1 (CPT1A), Acetil-CoA Carboxilase (ACC) e enzimas Oxidase Alternativa (AOX), os reguladores-chave da oxidação de ácidos graxos, também foram observados (ROBEY et al., 2015; BALABAN et. al., 2015).

Através da lipólise, os triglicerídeos intracelulares podem desempenhar um papel crítico no apoio aos substratos para a síntese lipídica complexa, bem como para a produção de energia nas células cancerosas que promovem coletivamente o crescimento e proliferação celular (BALABAN et al., 2015). As enzimas lipolíticas, como a Triacilglicerol Lipase (ATGL), Lipase Hormônio-sensível (HSL) e Monoacilglicerol Lipase (MAGL), foram encontradas aumentadas em cânceres ovarianos, colorretal, de mama, células de câncer de melanoma e em particular em linhas celulares de câncer de próstata agressivo (ROBEY et al., 2015; AL-ZHOUGHBI et al., 2014). O entendimento do metabolismo normal de lipídios nas células (Figura 1), possibilita compreender como essas alterações descritas nas células cancerosas podem favorecê-las (BALABAN et al., 2015).

Alterações na membrana celular também estão presentes em células cancerosas e influenciam na manutenção e proliferação das mesmas, já que a composição lipídica (relação de ácidos graxos saturados e insaturados) altera severamente na fluidez da membrana e na dinâmica das proteínas. Um aumento em fosfolípidios saturados, por exemplo, altera a transdução de sinal, protege as células cancerosas do dano oxidativo, tais como a peroxidação lipídica e, potencialmente, inibe a absorção de fármacos quimioterapêuticos (AYALA; MUÑOZ; ARGÜELLES, 2014).

As membranas celulares contêm diferentes classes de lipídios, estando entre eles o colesterol e os esfingolipídios, os quais formam microdomínios planares específicos, conhecidos como jangadas lipídicas ("lipids rafts"), elas estão aumentadas em células cancerosas e funcionam como plataformas para a sinalização celular, tendo proteínas de sinalização (AKT), receptores acoplados a proteína G, RTK (um receptor tirosina quinase), incluindo o receptor do fator de crescimento (GFR), e CXCR4 (um receptor de quimiocina) (BELORIBI-DJEFAFLIAL; VASSEUR; GUILLAUMOND, 2016). Uma vez ativados pelos seus respectivos ligantes, os receptores recrutam diferentes efetores de sinalização que promovem a sobrevivência celular, a migração celular e invasão da célula, o que contribui para o crescimento do tumor (Figura 2) (BELORIBI-DJEFAFLIAL; VASSEUR; GUILLAUMOND, 2016; LLAVERIAS et al., 2010). 

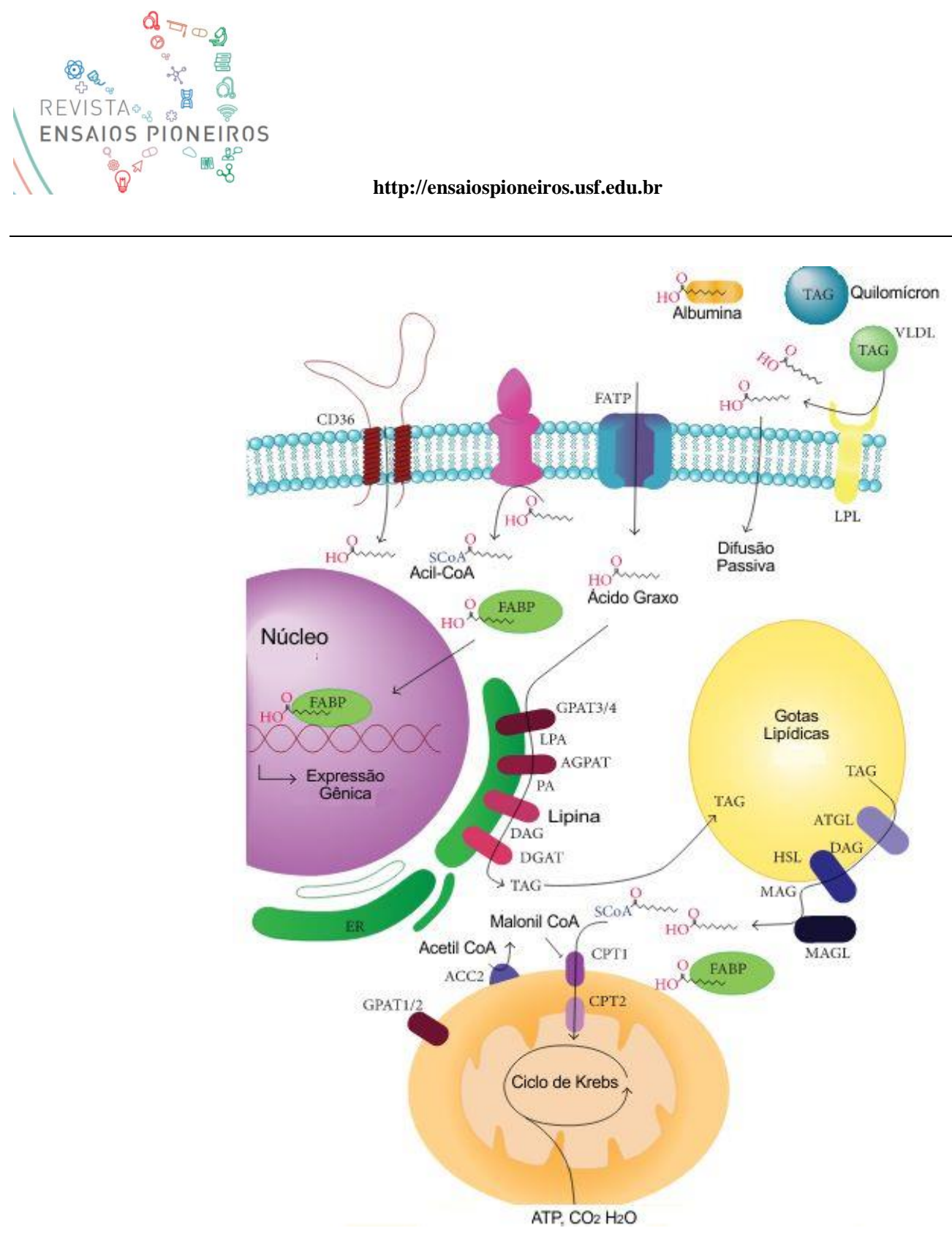

Figura 1 - Metabolismo intracelular dos ácidos graxos (BALABAN, 2015).

Outras funções dos lipídios relacionadas com o câncer são: a promoção da inflamação e da angiogênese, as quais ocorrem através das vias do ácido araquidônico, o qual é derivado do colesterol. Após a ação das enzimas Ciclooxigenases, Lipoxigenases, Citrocromo P450, agentes prós-inflamatórios e pró-angiogênicos (prostaglandinas, tromboxanos, prostaciclina e leucotrienos) são produzidos, os quais estimulam a proliferação celular e a formação de novos vasos sanguíneos, fatores essenciais na carcinogênese (SCHNEIDER; POZZI, 2011; DEMARIA et al., 2010; WANG; DUBOIS, 2010). 


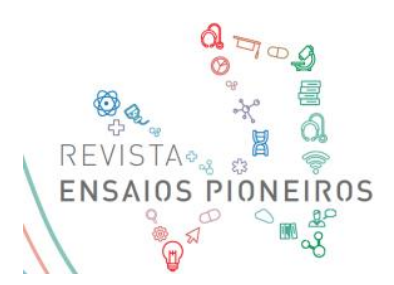

http://ensaiospioneiros.usf.edu.br



Figura 2 - Jangadas lipídicas como plataformas para sinalização celular (BELORIBIDJEFAFLIAL, 2016).

Outro mecanismo pelo qual o câncer utiliza os lipídios é pela comunicação com o estroma presente no microambiente. Dados sugerem que as células cancerígenas são capazes de induzir células estromais (adipócitos, por exemplo) para modificar o seu metabolismo e secretar espécies de lipídios que são, subsequentemente importados para promover o crescimento do tumor (ACKERMAN et al., 2014). Esse diálogo entre as células neoplásicas e o estroma ocorre através de lipídios bioativos secretados pelas células do câncer, como a Prostaglandina $\mathrm{E}_{2}\left(\mathrm{PGE}_{2}\right)$ e a Esfingosina-1-fosfato (S1P), ambas exercem os seus efeitos sobre as células do estroma através de mecanismos parácrinos (LOUIE; ROBERTS; NOMURA, 2013). A PGE 2 , transportada ou não por vesículas de membrana (exossomos), promove a angiogênese e também imunossupressão, além disso, a $\mathrm{PGE}_{2}$ também induz a secreção de quinurenina por fibroblastos adjacentes ao câncer, que por sua vez, promove a capacidade de invasão dessas células. Já a S1P, pela sua ligação no seu receptor específico, promove a proliferação de células cancerosas e angiogênese/linfangiogênese de forma autócrina e parácrina, respectivamente (LOUIE; ROBERTS; NOMURA, 2013). Os exossomos do microambiente tumoral do estroma também afetam essas células, pois eles contêm níveis elevados de lipídios no interior da membrana e na luz, tornando-se fontes de lipídios extracelulares que podem ser internalizados por essas células, influenciando na morte celular induzida pelo estresse do retículo endoplasmático, causado pela alta concentração lipídica celular (Figura 3) (BELORIBI-DJEFAFLIAL, 2016; LOUIE; ROBERTS; NOMURA, 2013; AL-ZHOUGHBI et al., 2014). 



Figura 3 - Comunicação Câncer-Estroma (BELORIBI-DJEFAFLIAL, 2016).

Estudos recentes revelaram que o metabolismo dos lipídios é também ligado à autofagia, um mecanismo de auto-degradação que é necessário para a remoção de proteínas e organelas defeituosas, a qual é induzida sob condições limitantes de nutrientes. Lipídios são componentes integrais do processo de autofagia e podem impactá-la em diferentes níveis; por exemplo, uma das etapas de iniciação da autofagia envolve a ligação da fosfatidiletanolamina à proteína Atg8/LC3 (proteína relacionada à autofagia). Curiosamente, a liberação dos lipídios a partir de gotas lipídicas em resposta à fome de nutrientes, requer componentes da maquinaria autofágica, incluindo Atg5 (outra proteína ligada à autofagia), esse modo de mobilização de lipídios de reservas intracelulares foi consequentemente denominado "macrolipofagia". A ligação entre o metabolismo lipídico e a autofagia é particularmente interessante, e cada vez mais provas confirmam a importância desse mecanismo no câncer. Como já demonstrado, a autofagia permite que as células com mutação no gene K-RAS mantenham o seu fornecimento de energia durante a necessidade de nutrientes $\mathrm{e}$ tumorigênese, esses resultados mostram a utilização de lipídios pelo processo de autofagia como um dos mecanismos de sobrevivência do câncer (BAENKE et al., 2013; BOROUGHS; DEBERARDINIS, 2015).

Outro estudo também mostrou que a dieta rica em gorduras saturadas desempenhou alterações nos micro-RNA's do esperma de ratos, e este evento foi relacionado com um maior risco no desenvolvimento de câncer de mama em sua prole feminina, ao contrário do experimento com a dieta rica em gorduras poliinsaturadas. Os mecanismos pelos quais a dieta rica em gordura altera o padrão de expressão de genes ainda não foram totalmente esclarecidos, porém, essas novas descobertas podem proporcionar o melhor entendimento da 
influência desse tipo de alimentação nos genes (FONTENELLES; GUIDO; ROSIM, 2016).

\section{Perspectivas terapêuticas}

Em relação à gordura exógena proveniente da dieta, da qual se baseou essa revisão, alguns autores têm mostrado que as gorduras são tratadas de forma diferente pelo organismo, sendo que as saturadas têm sido mais associadas ao desenvolvimento de câncer em relação às poliinsaturadas, que demonstraram efeito terapêutico nesses casos (OSTAN et al., 2015; SUBURU; CHEN, 2012; PELSER et al., 2013; FONTENELLES; GUIDO; ROSIM, 2016).

Um dos alvos terapêuticos das gorduras polinsaturadas apontado nas pesquisas inclui a ação de ERO's (Espécies Reativas de Oxigênio), as quais estão aumentadas nas células cancerígenas devido à disfunção mitocondrial e metabólica, sendo que a ação do estresse oxidativo sobre essas gorduras promove o aumento de produtos da peroxidação lipídica como o 4-hidroxinonenal e o malondialdeído, os quais têm demonstrado ação anti-tumoral devido a toxicidade e ação mutagênica, tornando-os assim possíveis alvos de estudo terapêutico (AYALA; MUÑOZ; ARGÜELLES, 2014). Os níveis de produtos da peroxidação de lipídios também podem ser utilizados para monitorizar o progresso e / ou avaliar a eficácia de terapia ou cirurgia em pacientes com câncer, uma vez que seus níveis têm acompanhado o desenvolvimento do mesmo (EREJUWA; SULAIMAN; WAHAB, 2013).

Outros estudos em humanos também têm mostrado que a dieta de ácidos graxos $\omega-3$ poliinsaturados, em particular, o ácido eicosapentaenóico (EPA, 20: 5w-3) e o ácido

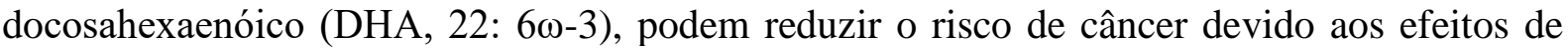
seus mediadores lipídicos como a prostaglandina $\mathrm{E}_{3}$, derivada da ciclooxigenase (COX); o 4hidroxi-ácido docosahexaenóico (4-HDHA), proveniente da lipoxigenase; ácido epóxi docosapentaenóico (AEPD) derivado do citocromo P450, bem como exclusivos autacóides lipídicos $\omega-3$, como as resolvinas e protectinas (BERQUIN et al., 2011).

Estes mediadores lipídicos de $\omega$-3 servem como mediadores parácrinos para regular a inflamação e a homeostase; muitos destes mediadores são de vida curta, produzidos localmente em resposta aos estímulos celulares, seguidos da degradação ou metabolismo dos mesmos (BERQUIN et. al., 2011). Os ácidos graxos $\omega$-3 poliinsaturados promovem essa ação interferindo ou inibindo a via das enzimas ciclooxigenases, lipoxigenases e citocromo P450 e consequentemente diminuindo o nível de mediadores químicos participantes da inflamação, angiogênese, proliferação celular e apoptose (CARMO; CORREIA, 2009; BERQUIN et. al., 2011).

\section{CONSIDERAÇÕES FINAIS}

Com base nas bibliografias pesquisadas, podemos observar que os lipídios provenientes da dieta certamente influenciam no processo carcinogênico através de vários mecanismos, obviamente, em colaboração a outros fatores etiológicos. Porém, o entendimento acerca dos tipos de lipídios e seus efeitos sobre o organismo, e especificamente sobre o câncer, ainda necessita ser desenvolvido através de mais pesquisas que possam esclarecer as vias moleculares e genéticas pelos quais essa influência da dieta é exercida. Ao mesmo tempo, a variabilidade de ação dos efeitos lipídicos sobre o câncer também permite a abertura de novas opções para tratamento e até mesmo prevenção.

Esse trabalho, portanto, juntamente com outros estudos, vem enfatizar a importância da compreensão do fator dietético sobre a biologia do câncer, e a sua futura utilidade para fins terapêuticos e preventivos. 
Concluímos com este estudo, que a partir do conhecimento da relação entre dieta rica em gordura como um fator de risco no processo carcinogênico, uma mobilização e conscientização social possam ocorrer. Visto que o consumo de gorduras nas dietas inadequadas e a obesidade são fatores de risco tanto para as Doenças Cardiovasculares como para o Câncer - a primeira e a segunda causa de morte mundial, respectivamente - cria-se a necessidade de medidas governamentais mais efetivas através de Políticas Públicas de Saúde que consigam reduzir o consumo das gorduras e promover uma dieta mais equilibrada entre os indivíduos.

\section{REFERÊNCIAS}

ABRAMCZYK, H. et al. The role of lipid droplets and adipocytes in cancer. Raman imaging of cell cultures: MCF10A, MCF7, and MDA-MB-231 compared to adipocytes in cancerous human breast tissue. The Analyst, v. 140, n. 7, p.2224-2235, 2015.

ACKERMAN, D. et al. Hypoxia, lipids, and cancer: surviving the harsh tumor microenvironment. Trends In Cell Biology, v. 24, n. 8, p.472-478, 2014.

AL-ZHOUGHBI, W. et al. Tumor Macroenvironment and Metabolism. Seminars In Oncology, v. 41, n. 2, p.281-295, 2014.

ARANHA, F. L. Bioquímica didática: volume único. São Paulo: Copola Livros. 1998.

ARNOT,W. T.The Breast cancer Prevention Diet. São Paulo: Objetiva, 1998.

AYALA, A.; MUÑOZ, M. F.; ARGÜELLES, S. Lipid Peroxidation: Production, Metabolism, and Signaling Mechanisms of Malondialdehyde and 4-Hydroxy-2-Nonenal. Oxidative Medicine And Cellular Longevity, v. 2014, p.1-31, 2014.

BAENKE, F. et al. Hooked on fat: the role of lipid synthesis in cancer metabolism and tumour development. Disease Models \& Mechanisms, v. 6, n. 6, p.1353-1363, 2013.

BALABAN, S. et al. Obesity and Cancer Progression: Is There a Role of Fatty Acid Metabolism? Biomed Research International, v. 2015, p.1-17, 2015.

BAYNES, J. W.; DOMINICZAK, M. H. Bioquímica médica. $3^{\text {a }}$ ed. Rio de Janeiro: Elsevier, 2010.

BELORIBI-DJEFAFLIAL, S. VASSEUR, S.; GUILLAUMOND, F. Lipid metabolic reprogramming in cancer cells. Oncogenesis, v. 5, n. 1, e189, 2016.

BERQUIN, I. M. et al. Polyunsaturated fatty acid metabolism in prostate cancer. Cancer Metastasis Rev, v. 30, n. 3-4, p.295-309, 2011.

BOROUGHS, L. K.; DEBERARDINIS, R. J. Metabolic pathways promoting cancer cell survival and growth. Nature Cell Biology, v. 17, n. 4, p.351-359, 2015.

BRASIL. Ministério da Saúde. INCA - Instituto Nacional de Câncer José Alencar Gomes da 
Silva. Estimativa 2016: Incidência de câncer no Brasil. Rio de Janeiro: INCA, 2016.

CARMO, M. C. N. S.; CORREIA, M. I. T. D. A Importância dos Ácidos Graxos Ômega-3 no Câncer. Revista Brasileira de Cancerologia, v. 55, n. 3, p. 279-287, 2009.

CURI, R. et al. Entendendo a Gordura: Os ácidos graxos. Editora Manole Ltda, 2001 - 580 p.

DE ROBERTIS, E. M. F; HIB, J. Base da Biologia Celular e Molecular. $4^{\mathrm{a}}$ ed. Rio de Janeiro: Guanabara koogan, 2006.

DEBERARDINIS, R. J.; CHANDEL, N. S. Fundamentals of cancer metabolism. Science Advances, v. 2, n. 5, e1600200, 2016.

DEMARIA, S. et al. Cancer and Inflammation: Promise for Biologic Therapy. Journal Of Immunotherapy, v. 33, n. 4, p.335-351, 2010.

EREJUWA, O. O.; SULAIMAN, S. A.; WAHAB, M. S. A. Evidence in Support of Potential Applications of Lipid Peroxidation Products in Cancer Treatment. Oxidative Medicine And Cellular Longevity, v. 2013, p.1-8, 2013.

FELICIO, P. E. D. Dieta Ocidental e Saúde: alguns erros históricos. Revista ABCZ, Uberaba, ano 5, n.26, 2005.

FONTENELLES, C. C.; GUIDO, L. N.; ROSIM, M. P. et al. Paternal programming of breast cancer risk in daughters in a rat model: opposing effects of animal- and plant-based high-fat diets. Breast Cancer Research, v. 18, n. 71, 2016.

HANAHAN, D.; WEINBERG, R. A. Hallmarks of Cancer: The Next Generation. Cell, v. 144, n. 5, p.646-674, 2011.

LLAVERIAS, G. et al. A Western-type diet accelerates tumor progression in an autochthonous mouse model of prostate cancer. The American journal of pathology, v. 177, n. 6, p. 3180-3191, 2010.

LOUIE, S. M.; ROBERTS, L. S.; NOMURA, D. K. Mechanisms linking obesity and cancer. Biochimica Et Biophysica Acta (bba) - Molecular And Cell Biology Of Lipids, v. 1831, n. 10, p.1499-1508, 2013.

MARZZOCO, Anita; TORRES, Bayardo Baptista. Bioquímica básica. 3. ed. Rio de Janeiro: Guanabara Koogan, 2007.

MOTTA, V.T. Bioquímica Básica. São Paulo-SP: Autolab, 2003.

MUÑOZ-PINEDO, C; MJIYAD, N. El; RICCI, J-E. Cancer metabolism: current perspectives and future directions. Cell Death Dis, v. 3, n. 1, p.248-249, 2012.

NELSON, D. L.; COX, M. M. Lehninger: Princípios de Bioquímica. $3^{\text {a }}$ ed. São Paulo, 
Brasil: Editora Sarvier, 2002.

OSTAN, R. et al. Inflammaging and Cancer: A Challenge for the Mediterranean Diet. Nutrients, v. 7, n. 4, p.2589-2621, 2015.

PELSER, C. et al. Dietary Fat, Fatty Acids, and Risk of Prostate Cancer in the NIH-AARP Diet and Health Study. Cancer Epidemiology Biomarkers \& Prevention, v. 22, n. 4, p.697707, 2013.

RAFALSKI, V. A; MANCINI, E; BRUNET, A. Energy metabolism and energy-sensing pathways in mammalian embryonic and adult stem cell fate. Journal of Cell Science, v. 125, n. 23, 2012.

ROBEY, R. B. et al. Metabolic reprogramming and dysregulated metabolism: cause, consequence and/or enabler of environmental carcinogenesis? Carcinogenesis, v. 36, n. 1, p.203-231, 2015.

SACKHEIM, G. I.; LEHMAN, D. D. Química e Bioquímica para Ciências Biomédicas. $1^{\mathrm{a}}$ ed. Barueri: Editora Manole, 2001.

SANTOS, R. D. et al. I Diretriz sobre o consumo de gorduras e saúde cardiovascular. Arq. Bras. Cardiol. São Paulo, v. 100, n. 1, supl. 3, p. 1-40, Jan. 2013.

SCHNEIDER, C.; POZZI, A. Cyclooxygenases and lipoxygenases in cancer. Cancer Metastasis Rev, v. 30, n. 3-4, p.277-294, 2011.

SUBURU, J.; CHEN, Y. Q. Lipids and prostate cancer. Prostaglandins \& Other Lipid Mediators, v. 98, n. 1-2, p.1-10, 2012.

UCKO, D. A. Química para as ciências a Saúde: uma introdução à química geral, orgânica e biológica. $2^{\text {a }}$ ed., São Paulo: Editora Manole, 1992.

VOET, D.; VOET, J.; PRATT, C. W. Fundamentos de bioquímica: a vida em nível molecular. 4. ed. Porto Alegre: Artmed, 2014.

WANDERLEY, E. N.; FERREIRA, V. A. Obesidade: uma perspectiva plural. Ciênc. Saúde Coletiva, v. 15, n. 1, p.185-194, 2010.

WANG, D.; DUBOIS, R. N. Eicosanoids and cancer. Nature Reviews Cancer, v. 10, n. 3, p.181-193, 2010. 